\title{
Physiological Aspects of Plasma Osmolarity and its Association with the Clinical Severity of Ischemic Stroke Evaluated with the NIHSS: A Cross-sectional Study
}

\author{
Yusak Mangara Tua Siahaan ${ }^{1,2 *}$ (D) ${\text { Vinson } \text { Hartoyo }^{1} \text { (D) } \text { Michelle Muljono }^{1} \text { (D), Trianggoro Budisulistyo }}^{3,4,5}$ (D) \\ ${ }^{1}$ Department of Neurology, Siloam Hospitals Lippo Village, Tangerang, Indonesia; ${ }^{2}$ Department of Neurology, Faculty of Medicine, \\ Pelita Harapan University, Tangerang, Indonesia; ${ }^{3}$ Department of Neurology, Dr. Kariadi Central General Hospital, Semarang, \\ Indonesia; ${ }^{4}$ Department of Neurology, Siloam Hospitals Semarang, Semarang, Indonesia; ${ }^{5}$ Department of Neurology, Faculty \\ of Medicine, Diponegoro University, Semarang, Indonesia
}

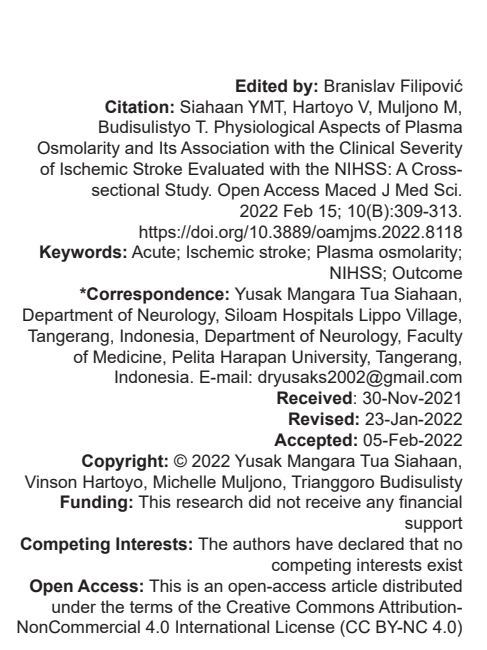

\section{Abstract}

BACKGROUND: Ischemic stroke is one of the leading causes of mortality and disability worldwide. Recent studies have observed that some physiological factors play a pivotal role in determining stroke severity, which can be assessed using the National Institutes of Health Stroke Scale (NIHSS) score. Hydration status is one of the most frequently studied physiological factors and can be evaluated by measuring plasma osmolarity levels. However, studies regarding the association between plasma osmolarity and stroke severity remain scarce.

AIM: This study aimed to investigate the association between increased blood plasma osmolarity levels and the NIHSS scores in patients with acute ischemic stroke.

METHODS: This cross-sectional study obtained medical records of subjects aged 18-80 years old who were diagnosed with their first acute ischemic stroke from January to March 2021 at the Siloam Hospitals Lippo Village Tangerang in Indonesia.

RESULTS: The NIHSS scores of patients with acute ischemic stroke were observed to have a moderate positive correlation with plasma osmolarity $(p=0.004, r=0.309)$. Patients with an elevated plasma osmolarity had higher NIHSS scores than those with normal levels of plasma osmolarity $(8.52 \pm 5.01$ vs. $6.03 \pm 3.72)$.

CONCLUSIONS: Higher levels of plasma osmolarity among acute ischemic stroke subjects correlated positively with increased NIHSS scores on admission.

\section{Introduction}

Stroke is a neurological disease with the highest prevalence worldwide, based on the World Health Organization (WHO) survey. At present, stroke is the second leading cause of death, with an annual mortality rate of 5.5 million people [1], [2]. Stroke is one of the most disability-causing diseases globally. It was found that $50 \%$ of patients with stroke experience permanent disability with varying degrees of severity [2]. With increasing progress in healthcare quality, the global life expectancy continues to increase, thus shifting the prevalence of diseases toward metabolic and degenerative diseases, along with an increase in global stroke prevalence, including Indonesia [1], [2], [3], [4].

As stroke research progresses, multiple scales have been developed to measure the severity of stroke. The National Institutes of Health Stroke
Scale (NIHSS) is one of the best scoring systems for assessing the severity of stroke symptoms [5], [6]. In addition to the NIHSS, several other parameters that are potentially correlated to the clinical severity of stroke have also been studied, including plasma osmolarity levels. Increased plasma osmolarity is associated with dehydration, and some studies have shown its relation to increased mortality in patients with severe clinical disorders such as cardiac, cerebral, vascular, and gastrointestinal disorders. It is also particularly associated with prolonged admission and increased mortality rates in intensive care patients [7], [8], [9].

Comprehensive management of stroke is essential for better patient outcomes. We hypothesized that the hydration state, which is determined by patients' plasma osmolarity levels, correlates with the outcome of patients with acute ischemic stroke, and that it can act as a new indicator to treat stroke patients for a better outcome. Therefore, the present study was conducted. 


\section{Methods}

This was a hospital-based cross-sectional study conducted between January and March 2021 at the Siloam Hospitals Lippo Village. The research data collected are secondary data from the medical records of patients suffering from acute ischemic stroke for the 1 time. Data were gathered using consecutive sampling based on the inclusion criteria of patients between the ages of 18 and 80 years diagnosed with the first ischemic stroke attack. Patients with an altered level of consciousness, systemic infection, chronic kidney disease, prior history of head trauma within 3 months, and incomplete medical records were excluded from the study.

The NIHSS score was measured at admission, formula: 2 [serum sodium level, $\mathrm{Na}+$ ] + [glucose]/18 + [blood urea nitrogen, BUN]/2.8. Plasma osmolarity was considered a dichotomous variable, with an upper limit of $295 \mathrm{mOsm} / \mathrm{L}$. Diagnosis of ischemic stroke was made by neurologists based on physical examination and was confirmed with computed tomography to rule out other acute brain disorders.

Information collected for demographic data and the NIHSS score at first hospital admission included history of hypertension, diabetes mellitus (DM), dyslipidemia, heart disease, smoking, and metabolic panels (sodium, glucose, and BUN levels).

\section{Data analysis}

Data were collected using provided research form. Data were then edited, coded and organized using SPSS version 24.0 software. Statistical analysis was performed using statistic test which appropriate with research variables measurement scale. Tests of normality were carried out using the Kolmogorov test, as the samples included were more than 50 . The data were considered to have a normal distribution if the $p$-value was $>0.05$. Statistical analyses were performed using Pearson's correlation for data with a normal distribution. The Spearman rank correlation method was used to assess the association of increased plasma osmolarity level and NIHSS scores $(p<0.05)$.

\section{Ethical clearance}

Ethical clearance was obtained from The Ethics Committee of Pelita Harapan University with ethical review number: 041VK-LKJ/ETI/I/2021.

\section{Results}

A total of 73 subjects were included in this study, with a predominance of males $(57.53 \%)$. Most while plasma osmolarity was calculated using the

patients were aged between 51 and 60 years old $(34.25 \%, \mathrm{n}=25)$. Most of the patients had a history of hypertension (83.56\%), followed by dyslipidemia $(52.05 \%)$, DM $(32.88 \%)$, and heart disease $(12.33 \%)$. The mean plasma osmolarity level of this patient cohort was $296.67 \pm 7.80 \mathrm{mOsm} / \mathrm{L}$, while the mean NIHSS score was $7.47 \pm 4.68$ (Table 1$)$.

Table 1: Baseline characteristics of subjects $(n=73)$

\begin{tabular}{ll}
\hline Characteristics & Frequency (\%) \\
\hline Gender & $42(57.53)$ \\
Male & $31(42.47)$ \\
Female & \\
Age, $\mathrm{n}(\%)$ & $18(24.66)$ \\
$41-50$ years old & $25(34.25)$ \\
$51-60$ years old & $20(27.40)$ \\
$61-70$ years old & $10(13.70)$ \\
$71-80$ years old & \\
Occupation, $\mathrm{n}(\%)$ & $38(52.05)$ \\
Working & $35(47.95)$ \\
Not working & \\
Smoking, n (\%) & $39(53.42)$ \\
Yes & $34(46.58)$ \\
No & \\
Medical history, $n$ (\%) & $61(83.56)$ \\
Hypertension & $38(52.05)$ \\
Dyslipidemia & $24(32.88)$ \\
Diabetes mellitus & $9(12.33)$ \\
Heart diseases & $7.47( \pm 4.68)$ \\
Mean NIHSS score (SD) & $296.67( \pm 7.80)$ \\
Mean plasma osmolarity (mOsm/L) (SD) &
\end{tabular}

The Pearson's correlation test revealed a moderately significant positive correlation between plasma osmolarity level and NIHSS score, with a positive tendency $(p=0.004, r=0.309)$. These results suggest that elevated plasma osmolarity is significantly associated with worse clinical symptoms of ischemic stroke patient which is showed by an increase in the NIHSS score.

Table 2: Analysis of risk factors to NIHSS score in patients with normal and elevated plasma osmolarity

\begin{tabular}{|c|c|c|c|}
\hline Variable & Mean NIHSS score \pm SD & Minimum - Maximum & $\mathrm{p}$-value \\
\hline \multicolumn{4}{|l|}{ NIHSS score $(n=73)$} \\
\hline Normal plasma osmolarity & $6.03 \pm 3.72$ & $0-12$ & \multirow[t]{2}{*}{$0.023^{*}$} \\
\hline Elevated plasma osmolarity & $8.52 \pm 5.01$ & $2-29$ & \\
\hline \multicolumn{4}{|l|}{ Male $(n=42)$} \\
\hline Normal plasma osmolarity & $5.16 \pm 3.27$ & $0-11$ & \multirow[t]{2}{*}{$0.002^{*}$} \\
\hline Elevated plasma osmolarity & $10.00 \pm 5.47$ & $3-29$ & \\
\hline \multicolumn{4}{|l|}{ Female $(n=31)$} \\
\hline Normal plasma osmolarity & $7.42 \pm 4.10$ & $0-12$ & \multirow[t]{2}{*}{0.653} \\
\hline Elevated plasma osmolarity & $6.74 \pm 3.96$ & $2-14$ & \\
\hline \multicolumn{4}{|l|}{ Smoking $(n=39)$} \\
\hline Normal plasma osmolarity & $8.54 \pm 2.93$ & $4-12$ & \multirow[t]{2}{*}{0.252} \\
\hline Elevated plasma osmolarity & $10.35 \pm 5.18$ & $2-29$ & \\
\hline \multicolumn{4}{|c|}{ Not smoking $(n=34)$} \\
\hline Normal plasma osmolarity & $4.35 \pm 3.22$ & $0-10$ & \multirow[t]{2}{*}{0.372} \\
\hline Elevated plasma osmolarity & $5.35 \pm 3.22$ & $2-12$ & \\
\hline \multicolumn{4}{|c|}{ Diabetes melitus $(n=24)$} \\
\hline Normal plasma osmolarity & $6.36 \pm 2.80$ & $3-8$ & \multirow{2}{*}{0.100} \\
\hline Elevated plasma osmolarity & $9.08 \pm 4.56$ & $3-16$ & \\
\hline \multicolumn{4}{|c|}{ Non-diabetes mellitus $(n=49)$} \\
\hline Normal plasma osmolarity & $6.05 \pm 4.21$ & $0-12$ & \multirow[t]{2}{*}{0.172} \\
\hline Elevated plasma osmolarity & $8.07 \pm 5.36$ & $2-29$ & \\
\hline \multicolumn{4}{|c|}{ Hypertension $(n=61)$} \\
\hline Normal plasma osmolarity & $6.27 \pm 3.37$ & $0-12$ & \multirow[t]{2}{*}{0.087} \\
\hline Elevated plasma osmolarity & $8.44 \pm 5.25$ & $2-29$ & \\
\hline \multicolumn{4}{|c|}{ Non-hypertension $(n=12)$} \\
\hline Normal plasma osmolarity & $5.88 \pm 4.76$ & $0-12$ & \multirow[t]{2}{*}{0.513} \\
\hline Elevated plasma osmolarity & $7.75 \pm 3.86$ & $4-12$ & \\
\hline \multicolumn{4}{|c|}{ Dyslipidemia $(n=38)$} \\
\hline Normal plasma osmolarity & $7.69 \pm 3.56$ & $3-12$ & \multirow[t]{2}{*}{$0.028^{*}$} \\
\hline Elevated plasma osmolarity & $10.96 \pm 5.06$ & $2-29$ & \\
\hline \multicolumn{4}{|c|}{ Non-dyslipidemia $(n=35)$} \\
\hline Normal plasma osmolarity & $5.00 \pm 3.45$ & $0-12$ & \multirow[t]{2}{*}{0.820} \\
\hline Elevated plasma osmolarity & $4.78 \pm 2.13$ & $2-9$ & \\
\hline \multicolumn{4}{|l|}{ Heart diseases $(n=9)$} \\
\hline Normal plasma osmolarity & $7.50 \pm 0.70$ & $3-12$ & \multirow[t]{2}{*}{0.728} \\
\hline Elevated plasma osmolarity & $7.83 \pm 5.08$ & $2-29$ & \\
\hline \multicolumn{4}{|l|}{ Non-heart diseases $(n=64)$} \\
\hline Normal plasma osmolarity & $6.07 \pm 3.82$ & $0-12$ & \multirow[t]{2}{*}{0.063} \\
\hline Elevated plasma osmolarity & $8.35 \pm 5.17$ & $2-9$ & \\
\hline
\end{tabular}


The risk factors of stroke, such as sex, hypertension, DM, dyslipidemia, and heart disease, were all considered confounding factors. From the bivariate analysis, there was a significant difference in the NIHSS scores among subjects with dyslipidemia and increased plasma osmolarity levels compared to those with normal plasma osmolarity levels (10.96 \pm 5.06 vs. $7.69 \pm 3.56$, $p=0.028$ ) (Table 2). A significant difference in the NIHSS score was also observed among male subjects with increased plasma osmolarity levels compared to males with normal plasma osmolarity levels (10.00 \pm 5.47 vs. $5.16 \pm 3.27 ; p=0.002)$. The plasma osmolarity levels of other confounding factors such as smoking, hypertension, diabetes mellitus, and heart disease were not significantly associated with the NIHSS score.

\section{Discussion}

Our study reported a moderately significant positive association between elevated plasma osmolarity levels and increased NIHSS scores in patients with acute ischemic stroke which is confirmed from Pearson's correlation test ( $p=0.004, r=0.309)$. This finding signify that increased plasma osmolarity correspond with worse clinical symptom of ischemic stroke. Subsequently, a study by Riana et al. reported similar findings and stated a significant and moderate positive correlation between plasma osmolarity levels and clinical outcomes in acute stroke patients measured using the NIHSS score $(r=0.304, p=0.011)$ [10]. Another study by Brahmana also reported a significant and moderate relationship between plasma osmolarity and the NIHSS score ( $p=0.0001, r=0.564)$ [11].

An increase in plasma osmolarity is often found in patients who suffer from acute stroke [12], [13]. Several theories have been proposed to explain the high occurrence of elevated plasma osmolarity levels in acute stroke patients and the changes that occur in the body [14], [15], [16]. The first condition is dehydration, which is common in acute ischemic stroke, especially in elderly patients. A study by Rowat et al. found that $62 \%$ of all patients with acute stroke were dehydrated [17]. This dehydration is a result of decreased water intake caused by impaired consciousness and debilitated swallowing function (dysphagia), a complication of stroke. In addition, imbalance of electrolytes due to syndrome of inappropriate antidiuretic hormone (SIADH) can also cause disturbances in osmolarity component balance, which ultimately increases osmolarity levels [16], [17], [18], [19], [20]. Dehydration has been known to cause increased blood viscosity. Depending on at what rate it is measured, blood viscosity may be further divided into systolic blood viscosity which is measured at high shear rate and diastolic blood viscosity (DBV) which is measured at low shear rate. An elevated DBV in particular, can aggravate blood flow disturbance which is important to limit further tissue damage in ischemic stroke. It is also hypothesized that an elevated DBV may trigger novel acute lacunar infarct through endothelial remodeling and luminal occlusion in small vessels. Moreover, a study by Chang et al. reported that increased blood viscosity from dehydration also directly has a negative impact on development of collaterals in stroke patient particularly in patient with middle cerebral artery occlusion. Dehydration may cause decreased cerebral blood volume, blood velocity and intravascular volume thus resulting in a lower pressure gradient and ability to stimulate collateral recruitment which is pivotal to maintain perfusion in penumbral region to limit further injury in stroke [21], [22].

This study found a wide variation in the patients' NIHSS score, which may be due to age differences, location of the lesion, or other confounding risk factors. For example, several studies have found that lesions around the hypothalamus can specifically affect changes in osmolarity by over-secretion of the hormone vasopressin. Vasopressin can affect the hydro-mineral balance in cell membranes and the blood-brain barrier, which may cause brain edema. Increased vasopressin levels trigger an increase in the luminal activity of $\mathrm{Na}+$ / $\mathrm{H}+$ exchange (NHE) receptors 1 and 2, the amount of NHE1 $(\mathrm{Na}+/ \mathrm{H}+$ exchange receptors 1$)$, and the action of $\mathrm{Na}+/ \mathrm{K}+/ 2 \mathrm{Cl}$ water co-transport [19], [20] Fluid balance is quite difficult to manage, especially in elderly patients, as some symptoms and indications of dehydration are sometimes unclear and challenging to monitor. This condition can be exacerbated by several other disturbances, such as cortical dysfunction, which may lead to decreased thirst perception [23].

High plasma osmolarity levels are also associated with poor clinical outcomes of stroke because an increase in hematocrit levels can induce the release of erythrocyte-derived adenosine diphosphate (ADP), which worsens vascular occlusion [24], [25]. Furthermore, increased hematocrit levels may also harm endothelial cells due to the propagation of several mechanisms, such as lipid peroxidation, oxidative stress, and thrombin formation [25], [26]. These adverse effects can increase stroke severity, which is characterized by elevated NIHSS scores. Increased plasma osmolarity is also considered an inflammatory stimulus as it is accompanied by an increase in inflammatory cytokines such as tumor necrosis factor, interleukin-1ß, 6, and 8 (IL$1 ß, \mathrm{IL}-6$, and IL-8), which are considered highly potent in precipitating the worsening of ischemic stroke [27]. A study by Dmitreva et al. reported that even an acute slight increase in sodium (from 135 to $145-150 \mathrm{mmol} / \mathrm{L}$ ) in the presence of aldosterone stiffens endothelial cells and impairs nitric oxide release, thus increasing the risk of thrombotic event incidence [28]. This finding suggests that an increase in plasma osmolarity may exacerbate thrombotic event incidence, particularly in locations exposed to high shear stress, such as 
curvatures, ostia, and bifurcations. Furthermore, chronic elevation of plasma sodium levels may further damage the endothelium of the microvasculature due to the inflammatory effect of sodium.

The plasma osmolarity level, which is associated with a patient's hydration status, was also found to influence the occurrence of early neurological deterioration (END) in stroke through various mechanisms depending on the severity of the stroke. In mild stroke, END occurs by extension of ischemia to the initially asymptomatic (penumbra) cluster of neurons surrounding the core ischemic tissue. In severe stroke, this clinical deterioration is likely to occur through vasogenic edema and hemorrhagic transformation. The increase in osmolarity ultimately worsens the ischemic process in stroke by increasing blood viscosity and decreasing blood pressure, resulting in decreased perfusion to the brain tissue. Impaired brain perfusion worsens the clinical condition of stroke patients and is further exacerbated by various complications, such as seizures or death [29], [30].

\section{Conclusions}

Our study demonstrates that elevated plasma osmolarity levels were significantly associated with an increase in the NIHSS scores of patients with acute ischemic stroke, which signifies a worse clinical condition. In the acute phase, the hydration status of patients with ischemic stroke should become an essential variable for the comprehensive management of stroke to ensure a better clinical outcome. Our study had several limitations. The cross-sectional nature of our study limited the evaluation of trends or changes in the initial NIHSS score at admission and the NIHSS score at discharge. Several confounding factors that were not excluded, such as history of hypertension, DM, dyslipidemia, heart disease, and smoking behavior, might also have affected the results. We would suggest further research with bigger sample size and multiple point of entry for both NIHSS and osmolarity level.

\section{References}

1. Donkor ES. Stroke in the $21^{\text {st }}$ Century: A snapshot of the burden, epidemiology, and quality of life. Stroke Res Treat. 2018;2018:3238165. https://doi.org/10.1155/2018/3238165 PMid:30598741

2. Feigin VL, Norrving B, Mensah GA. Global burden of stroke. Circ Res. 2017;120(3):439-48. https://doi.org/10.1161/ CIRCRESAHA. 116.308413

PMid:28154096

3. Venketasubramanian N, Yoon W, Pandian J, Navarro C. Stroke epidemiology in South, East, and South-East Asia:
A review. J Stroke. 2017;19(3):286-94. https://doi.org/10.5853/ jos.2017.00234

PMid:29037005

4. Mukherjee D, Patil CG. Epidemiology and the global burden of stroke. World Neurosurg. 2011;76(6):S85-90. https://doi. org/10.1016/j.wneu.2011.07.023

PMid:22182277

5. Chalos V, van der Ende NA, Lingsma HF, Mulder MJ, Venema E, Dijkland SA, et al. National institutes of health stroke scale: An alternative primary outcome measure for trials of acute treatment for ischemic stroke. Stroke. 2020;51(1):282-90. https://doi.org/10.1161/strokeaha.119.026791

PMid:31795895

6. Williams LS, Yilmaz EY, Lopez-yunez AM. Retrospective assessment of initial stroke severity with the NIH stroke scale. Stroke. 2000;31(4):858-63. https://doi.org/10.1161/01. str.31.4.858

PMid:10753988

7. Bhalla A, Sankaralingam $S$, Dundas $R$, Swaminathan $R$, Wolfe CD, Rudd AG. Influence of raised plasma osmolality on clinical outcome after acute stroke. Stroke. 2000;31(9):2043-9. https://doi.org/10.1161/01.str.31.9.2043 PMid:10978027

8. Shen $\mathrm{Y}$, Cheng $\mathrm{X}$, Ying $\mathrm{M}$, Chang $\mathrm{H}$, Zhang W. Association between serum osmolarity and mortality in patients who are critically ill: A retrospective cohort study. BMJ Open. 2017;7:e015729. https://doi.org/10.1136/bmjopen-2016-015729 PMid:28490564

9. Khanam B, Mourya S, Patel VS, Sharma A. Association between plasma osmolarity and mortality in patients admitted in ICU at IMCHRC, Indore. Sch J Appl Med Sci. 2018;6(3):881-5.

10. Riana C. Relationship between Serum Albumin, Plasma Osmolarity and Clinical Outcome in Acute Stroke Patients. Medan: Sumatera Utara University; 2017.

11. Brahmana AR. Relationship between Plasma Osmolality and Hematoma Volume Towards Clinical Outcome in Stroke Patients. Medan: Sumatera Utara University; 2019.

12. Santos M, Barreira T, Carollina D, Silva C. Dehydration, stroke and dysphagia: Systematic review. Audiol Commun Res. 2019;24:1-9. https://doi.org/10.1590/2317-6431-2019-2236

13. Bahouth MN, Szanton RF. Primary 'dehydration' and acute stroke: A systematic research review. J Neurol. 2018;265(10):2167-81. https://doi.org/s00415-018-8799-6 PMid:29497817

14. Brocker C, Thompson DC, Vasiliou V. The role of hyperosmotic stress in inflammation and disease. Biomol Concepts. 2012;3(4):345-64. https://doi.org/10.1515/bmc-2012-0001 PMid:22977648

15. Tsai Y, Yang J, Lee I, Yang J, Lin L. Effects of dehydration on brain perfusion and infarct core after acute middle cerebral artery occlusion in rats: Evidence from high-field magnetic resonance imaging. Front Neurol. 2018;9:1-5. https://doi.org/10.3389/ fneur.2018.00786 PMid:30294297

16. Pross N. Effects of dehydration on brain functioning: A life-span perspective. Ann Nutr Metab. 2017;70 suppl 1:30-6. https://doi. org/10.1159/000463060

PMid:28614811

17. Rowat A, Graham C, Dennis M. Dehydration in hospitaladmitted stroke patients detection, frequency, and association. Stroke. 2012;43(4):857-9. https://doi.org/10.1161/ STROKEAHA.111.640821

PMid:22156691

18. Cortés-Vicente E, Guisado-Alonso D, Delgado-Mederos R, 
Camps-Renom P, Prats-Sánchez L, Martínez-Domeño A. Frequency, risk factors, and prognosis of dehydration in acute stroke. Front Neurol. 2019;10:1-6. https://doi.org/10.3389/ fneur.2019.00305

PMid:30984104

19. Ameli PA, Ameli NJ, Gubernick DM, Ansari S, Mohan S, Satriotomo I, et al. Role of vasopressin and its antagonism in stroke related edema. J Neurosci Res. 2014;92:1091-9. https:// doi.org/10.1002/jnr.23407

PMid:24823792

20. Jia S, Liu X, Wang SC, Wang Y. Vasopressin hypersecretionassociated brain edema formation in ischemic stroke: Underlying mechanisms. J Stroke Cerebrovasc Dis. 2016;25(6):1289-300. https://doi.org/10.1016/j.jstrokecerebrovasdis.2016.02.002 PMid:27068863

21. Song SH, Kim JH, Lee JH, Yun YM, Choi DH, Kim HY. Elevated blood viscosity is associated with cerebral small vessel disease in patients with acute ischemic stroke. BMC Neurol. 2017;17(20):1-10. https://doi.org/10.1186/s12883-017-0808-3 PMid:26801969

22. Chang SW, Huang YC, Lin LC, Yang JT, Weng HH, Tsai YH, et al. Effect of dehydration of collaterals in acute middle cerebral artery occlusion. Eur J Neurol. 2016;23(3):494-500. https://doi. org/10.1111/ene.12481

23. Ramthun M, Mocelin AJ, Daher V, Delfino A. Case report hypernatremia secondary to post-stroke hypodipsia: Just add water! NDT Plus. 2011;4:236-7. https://doi.org/10.1093/ndtplus/ sfr057

\section{PMid:25949488}

24. Salonen JT, Nyyssönen K, Korpela H, Tuomilehto J, Seppänen R, Salonen R. High stored iron levels are associated with excess risk of myocardial infarction in eastern Finnish men. Circulation.
1992;86(3):803-11. https://doi.org/10.1161/01.cir.86.3.803

PMid:1516192

25. Yang R, Wang A, Ma L, Su Z, Chen S, Wang Y, et al. Hematocrit and the incidence of stroke: A prospective, population-based cohort study. Ther Clin Risk Manag. 2018;14:2081-8. https://doi. org/10.2147/TCRM.S174961

PMid:30425503

26. Kerr DM, Fulton RL, Lees KR. Seven-day NIHSS is a sensitive outcome measure for exploratory clinical trials in acute stroke: Evidence from the virtual international stroke trials archive. Stroke. 2012;43(5):1401-3. https://doi.org/10.1161/ STROKEAHA.111.644484 PMid:22308254

27. Schwartz L, Guais A, Pooya M. Is inflammation a consequence of extracellular hyperosmolarity? J Inflamm. 2009;6(21):1-10. https://doi.org/10.1186/1476-9255-6-21

PMid: 19549308

28. Dmitrieva NI, Burg MB. Elevated sodium and dehydration stimulate inflammatory signaling in endothelial cells and promote atherosclerosis. PLoS One. 2015;10(6):1-22. https:// doi.org/10.1371/journal.pone. 0128870

PMid:26042828

29. Lin J, Jiang A, Ling M, Mo Y, Li M, Zhao J. Prediction of neurologic deterioration based on support vector machine algorithms and serum osmolarity equations. Brain Behav. 2018;8(7):e01023. https://doi.org/10.1002/brb3.1023

PMid:29888877

30. Martin AJ, Price Cl. A systematic review and meta-analysis of molecular biomarkers associated with early neurological deterioration following acute stroke. Cerebrovasc Dis. 2018;46:230-41. https://doi.org/10.1159/000495572 